\title{
Issues facing Africans in London with HIV infection
}

For several decades, periods of economic instability and violence have forced many Africans to seek refuge outside of their countries, even outside of their continent. As former colonies, the majority of African countries have civic, linguistic, and cultural links with countries in Europe, making European cities an obvious destination for migrant Africans. In 1991, 103700 black Africa born Africans were living in London. ${ }^{1}$ As sub-Saharan Africa has been hit hardest by the HIV/AIDS epidemic, ${ }^{23}$ people from Africa in the UK are at high risk of being HIV infected, as well as acquiring HIV infection or infecting their partner or children. African communities are the second largest group in the UK to be affected by HIV-1 after men who have sex with men. Also, there has been a steady increase in the proportion of HIV-1 infections presumed to be heterosexually acquired, rising from $1 \%$ of all reported HIV-1 infections in 1985 to $28 \%$ in $1994 .{ }^{4}$ Reports of black African people with AIDS have increased from $7 \%$ of all UK cases in 1990 to $24 \%$ in $1994 .{ }^{5}$

Uganda is one of the sub-Saharan African countries most affected by HIV. ${ }^{2}$ As a result, in the UK, the majority of both HIV-1 and AIDS cases thought to have been acquired heterosexually are associated with Uganda. ${ }^{56}$ In 1991, adult black Ugandans formed 7\% of the adult black African population in London, yet they comprised $59 \%$ of the reported AIDS cases among the adult black Africans living in London. ${ }^{5}$

\section{HIV in the African immigrant context}

Black African immigrants often come to London in order to escape severe circumstances such as war or political persecution. This sometimes means a hasty departure at little notice, leaving family, friends, savings, and proof of professional or academic qualifications behind. These African immigrants are generally highly skilled and educated but are often unemployed here. In the 1991 census, black Africans had one of the highest proportions of people with post school qualifications of any ethnic groups. In addition, they were the ethnic group with the highest proportion of qualified people who were unemployed; $14 \%$ compared with $4 \%$ for the census's white ethnic group. Also, the unemployment rate for black Africans was $30 \%$, three times the proportion for the census's white ethnic group. In a sample of 119 Ugandans residing in south east London, nearly half $(46 \%)$ were educated to diploma or degree level, ${ }^{7}$ yet $36 \%$ were unemployed. Even with proof, most of Africa's professional qualifications are not recognised in the UK and an insecure immigration status can hinder people from gaining employment or having access to support. Compared with other ethnic groups, black Africans in Britain have the lowest proportion of people owning their accommodation and the highest proportion of households who are sharing accommodation (7\%) and lacking or sharing a bathroom/lavatory (just over $5 \%$ ). ${ }^{1}$ High unemployment, financial insecurity, unsatisfactory accommodation resulting in high mobility, concerns over immigration status, and culture shock is the general backdrop upon which many HIV diagnoses are made in African communities.

\section{HIV in families}

Because it is predominantly heterosexually transmitted in Africans, HIV also affects women and their children. The proportion of African women exceeds African men in both HIV and AIDS reports both in London and in Africa. In London, women comprise $54 \%$ of reports of black African patients with AIDS and $60 \%$ of reported HIV infections presumed heterosexually acquired in Africa. ${ }^{5}$ Many mainstream HIV/AIDS centres now include support groups and other activities aimed specifically at meeting the needs of African women.

Between 1984 and 1995, $11 \%$ of black Africans with HIV infection who were receiving care from statutory providers, and $9 \%$ of reported AIDS cases among black Africans were infants infected through vertical transmission. ${ }^{5}$ In addition to maintaining their own physical and mental health, positive African parents in London have the added worry of future care for their children. Until recently, according to anecdotal information from adoption agencies, African children were often placed with non-African families or returned, alone, to Africa. A lack of African adoption and fostering services was named as the number one gap in services for HIV infected Africans in a survey of African HIV voluntary sector service providers ${ }^{7}$; however, there has been a clear response to fill this gap recently. Barnardo's Positive Options and several African organisations are working with social services to assist HIV positive African families to find relatives or other appropriate African carers. ${ }^{78}$

While efforts are being made to meet the needs of HIV positive African women, there appears to be a gap in services for heterosexual African men. ${ }^{7}$ It seems many heterosexual African men feel uncomfortable accessing HIV/ AIDS specialist support centres designed for men who have sex with men. ${ }^{7}$ A few African organisations are now starting heterosexual men's support groups, but appealing to this group remains difficult.

\section{Accessing health services}

Because sub-Saharan African patients often present at genitourinary medicine services with advanced stages of disease, ${ }^{9}$ they are faced with manifold therapeutic and psychosocial disease management issues simultaneously. In addition, African service users may need more support to resolve these difficulties quickly as was suggested in a survey of African clinic attenders in our own clinic. African attenders cited a lack of understanding of the healthcare system, a lack of knowledge about eligibility for care, different beliefs about health and the use of modern medicine, language problems, and fear of authority often brought about by insecure immigration status as barriers to accessing health care. ${ }^{10}$

\section{Confidentiality and stigma}

Concerns over confidentiality have been cited by African HIV voluntary sector service providers as the most common barrier to accessing services ${ }^{7}$ and concerns about confiden- 
tiality were spontaneously expressed by $97 \%$ of African clinic attenders. ${ }^{10}$ It seems that fear of discovery of one's HIV status by others from their home country leads many to avoid using HIV related services. Much of the concern over confidentiality stems from substantial levels of stigmatisation in African communities. While most communities continue to experience the stigma related to HIV/AIDS, stigmatisation of HIV in African communities has been extremely powerful.

\section{The community response}

Ugandan and other African communities in London have responded to their HIV/AIDS epidemic in a positive way, setting up a number of organisations to provide services to those affected and to increase awareness and prevention. Focus Consultancy identified 38 African led organisations providing HIV/AIDS information, advice, and support services to the Ugandan, Kenyan, Tanzanian, Zairean, Zambian, or Zimbabwean communities on a regular basis. ${ }^{11}$ Ugandans were the first African community in Britain to establish voluntary community organisations dealing with HIV positive people, and 26 of the 38 organisations surveyed were Ugandan. ${ }^{11}$ The majority of these organisations work round the clock on an unfunded, voluntary basis; only five of the 26 Ugandan organisations in the survey had received funding. ${ }^{11}$ Some countries are not represented by organisations, but even for those that are, the lack of funding for African work hinders a sustainable response to the epidemic and sparks concerns in African communities that non-Africans are assessing African needs.

\section{Political/ethnic conflict}

As political and ethnic conflict is often what brings Africans to London, there are many very separate groups within most African communities, but particularly the Ugandan community. Groups from northern Uganda raise concerns that the more established (that is, funded) organisations are staffed by groups from southern Uganda. Such political infighting has been known to cause organisational instability which makes funders nervous; in fact, such infighting recently provoked funders to cancel support for the oldest and largest organisation in the Ugandan community.

\section{New therapies}

The viral load test most widely used may be underestimating the true value of non-clade B African strains of virus. As a result, some Africans may be excluded from trials because this viral load test has given a false reading that was too low to allow them to participate. Patients with non-clade B strains must be allowed access to clinical trials. Monitoring viral load before and after therapy may be subject to the same error. Until the best viral load test for measuring nonclade B has been evaluated, genitourinary medicine physicians and companies enrolling patients in clinical trials should monitor viral load in African patients using more than one test.

Obviously, all African AIDS patients should be offered available antiviral regimens; however, there are some issues around therapy that may be specific to migrant African patients. For instance, while most Africans are here for the long term, many have spouses, children, and parents in Africa. Once patients begin therapy it may be difficult for them to return to their home country without terminating their antiviral therapy, as new therapies are not readily available or are extremely costly in Africa.

\section{Recommendations}

- Africans should be involved in the delivery of HIV/AIDS and other health services both on a organisational and individual basis. There is much untapped talent in African communities that could be used to improve the accessibility and appropriateness of health services for Africans, would engage the community with responsibility for their health care and improve cultural understanding among non-African health professionals.

- Funders should develop closer working relations with the organisations they choose to fund. African organisations need support from funders in developing monitoring mechanisms and other aspects of their organisation through long term funding commitments whenever possible.

- It is important African patients be included in trials and have access to new therapies. While some in the Ugandan community complain of having been "researched to death", apart from biological activity, trials in white homosexual men may provide little information about the delivery or impact of new therapies for African heterosexual men and women.

- Because substantial funding for each individual African ethnic group is unlikely to become available, African communities should make an attempt to unify. Current divisions and conflicts in the community seem to create one of the greatest barriers to funding because funders fear instability in the organisations they support. A united, representative, and democratic body with strong leadership would raise the profile of the African community and increase its bargaining power.

- Recent evidence suggests that the primary prevention efforts of African community organisations are having some effect. From both a humanitarian and a public health perspective, it is important to ensure that African communities develop and receive appropriate and understandable health promotion. As this is clearly best done by Africans taking the lead, funding and support for the work of African community organisations should be increased.

ANNE M MCMUNN ROY MWANJE

Academic Unit

Department of Genitourinary Medicine, King's College London SE5 9RS

1 OPCS 1991. Census.

2 Essex M, Mboup S, Kanki PJ, Kalengai MR, eds. AIDS in Africa. New York: Raven Press, 1993.

3 Haub C. New UN projections depict a variety of demographic features. Population Today. Population Reference Bureau, Inc, April 1997;25:1-3.

4 Bhatt C. HIV and black communities. 1 Looking at epidemiology. London: The HIV Project, 1995.

5 Low N, Paine K, Chisholm D, Obonyo N, Storkey M, Youssef S, Pozniak A. African communities in London: demography and the epidemiology and economics of HIV infection. London: King's College School of Medicine economics of HIV infecti

6 Del Amo J, Goh BT, Forster GE. AIDs defining conditions in Africans resident in the United Kingdom. Int $\mathcal{F}$ STD AIDS 1996;7:44-7.

7 McMunn AM, Mwanje R, Pozniak AL. An assessment of factors relating to health promotion $\mathcal{E}$ HIV prevention for Ugandan communities in southeas London. London: King's College School of Medicine and Dentistry, April 1997 (in progress).

8 Personal communication with Barnardo's Positive Options. London, 22 April 1997.

9 Low N, Paine K, Clark R, Mahalingam M, Pozniak A. AIDS survival and progression in black Africans living in south London, 1986-1994. Grogitourin Med 1996;72:12-6.

10 Paine K, Low N, Pozniak A. African people with HIV in London: social and cultural aspects. Presented at NTRHA HIV/AIDS Education Day: Ethnic Minorities and HIV.

11 Focus Consultancy. Social mapping of African communities for targeting HIV prevention. London, 1996. 